University of Nebraska - Lincoln

DigitalCommons@University of Nebraska - Lincoln

November 1998

\title{
The incorporation of Nickel and Phosphorus dopants into Boron- Carbon alloy thin films
}

D.N. Mcllroy

University of Idaho

S.-D. Hwang

University of Nebraska-Lincoln

K. Yang

University of Nebraska-Lincoln

N. Remmes

University of Nebraska-Lincoln

Peter A. Dowben

University of Nebraska-Lincoln, pdowben@unl.edu

See next page for additional authors

Follow this and additional works at: https://digitalcommons.unl.edu/physicsdowben

Part of the Physics Commons

Mcllroy, D.N.; Hwang, S.-D.; Yang, K.; Remmes, N.; Dowben, Peter A.; Ahmad, A.A.; Ianno, N.J.; Li, J.Z.; and Jiang, H.X., "The incorporation of Nickel and Phosphorus dopants into Boron-Carbon alloy thin films" (1998). Peter Dowben Publications. 105.

https://digitalcommons.unl.edu/physicsdowben/105

This Article is brought to you for free and open access by the Research Papers in Physics and Astronomy at DigitalCommons@University of Nebraska - Lincoln. It has been accepted for inclusion in Peter Dowben Publications by an authorized administrator of DigitalCommons@University of Nebraska - Lincoln. 


\section{Authors}

D.N. Mcllroy, S.-D. Hwang, K. Yang, N. Remmes, Peter A. Dowben, A.A. Ahmad, N.J. Ianno, J.Z. Li, and H.X. Jiang 


\title{
The incorporation of Nickel and Phosphorus dopants into Boron-Carbon alloy thin films
}

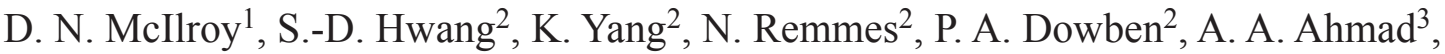 \\ N. J. Ianno ${ }^{3}$, J. Z. Li ${ }^{4}$, J. Y. Lin ${ }^{4}$, H. X. Jiang ${ }^{4}$
}

1 Department of Physics, University of Idaho, Moscow, ID 83844-0903; E-mail: dmcilroy@uidaho.edu
${ }^{2}$ Center for Materials Research and Analysis and the Department of Physics and Astronomy, University of Nebraska-Lincoln, Lincoln, NE 68588-0111
${ }^{3}$ Center for Microelectronics and Optical Materials and the Department of Electrical Engineering, University of Nebraska-Lincoln, Lincoln, NE 68588-0511
${ }^{4}$ Department of Physics, Kansas State University, Manhattan, KS 66506-2601

Submitted April 1997; accepted November 1997

\begin{abstract}
The structural and electronic properties of nickeland phosphorus-doped boron-carbon $\left(\mathrm{B}_{5} \mathrm{C}\right)$ alloy thin films grown by plasma-enhanced chemical vapor deposition have been examined. The Ni-doped boron-carbon alloys were grown using closo-1,2-dicarbadodecaborane $\left(\mathrm{C}_{2} \mathrm{~B}_{10} \mathrm{H}_{12}\right)$ as the boron-carbon source compound and nickelocene $\left(\mathrm{Ni}\left(\mathrm{C}_{5} \mathrm{H}_{5}\right)_{2}\right)$ as the nickel source. The phosphorus-doped alloys were grown using the single-source compound: dimeric chloro-phospha(III)-carborane $\left(\left[\mathrm{C}_{2} \mathrm{~B}_{10} \mathrm{H}_{10} \mathrm{PCl}\right]_{2}\right)$. Nickel doping increased the conductivity, relative to undoped $\mathrm{B}_{5} \mathrm{C}$, by six orders of magnitude from $10^{-9}$ to $10^{-3}(\Omega \mathrm{cm})^{-1}$ and transformed the material from a p-type semiconductor to an n-type. Phosphorus doping decreased the conductivity, relative to undoped $\mathrm{B}_{5} \mathrm{C}$, by two orders of magnitude and increased the band gap from $0.9 \mathrm{eV}$ for the undoped material to $2.6 \mathrm{eV}$. Infrared absorption spectra of the nickel-and phosphorus-doped $\mathrm{B}_{5} \mathrm{C}$ alloys were relatively unchanged from those of undoped $\mathrm{B}_{5} \mathrm{C}$. X-ray diffraction suggests that the phosphorus-doped material may be a different polytype from the Ni-doped and undoped $\mathrm{B}_{5} \mathrm{C}$ alloys.
\end{abstract}

With the growing demand for semiconductor materials which can operate at temperatures in excess of $200{ }^{\circ} \mathrm{C}$, alternatives to silicon are being sought. Although silicon carbide has excellent thermal properties, it is difficult to manufacture and package. Alternatives to silicon carbide are the boron-rich materials, in particular boron-carbon alloys. Like boron carbide, the boron-carbon alloys are refractory materials with melting temperatures in excess of $2400{ }^{\circ} \mathrm{C}$. These alloys typically have band gaps in excess of $0.7 \mathrm{eV}[1,2]$ and low numbers of free carriers [1].

Boron-carbon alloys have been successfully grown by the technique of plasma-enhanced chemical vapor deposition (PECVD) $\left[1,3^{-5}\right]$. The alloy forms of boron carbide have the chemical composition $\mathrm{B}_{5} \mathrm{C}$. The alloy materials typically have conductivities of $10^{-10}$ to $1^{0-12}(\Omega \mathrm{cm})^{-1}$ [1], compared to single-crystal boron carbide which has a conductivity of $1(\Omega \mathrm{cm})^{-1}[6]$. Similar conductivities $\left(10^{-8}(\Omega \mathrm{cm})^{-1}\right)$ have been observed for sputter-deposited boron-carbon alloy thin films [7]. Like crystalline boron carbide, the boroncarbon alloys consist of an icosahedral network $[1,8]$, where the icosahedra are composed of boron and carbon atoms. In contrast, the icosahedra in crystalline boron carbide, are almost exclusively constructed from boron atoms with the carbon atoms predominantly participating in the three atom chains that connect the icosahedral network [9-16]. The average crystallite size of the PECVD-grown alloys is approximately $100 \AA[1,8]$.

The PECVD process for growing boron-carbon alloys is well suited for semiconductor device manufacturing. Diodes and simple junction field effect transistors have been constructed from boron-carbon alloy thin films $[1,3,4,7]$. Typically, these devices have been constructed from boron-carbon thin films grown on either Si or a boron thin film. These studies demonstrated that simple devices could be successfully constructed from boron-carbon alloy materials, regardless of long-range crystallinity.

The $\mathrm{B}_{5} \mathrm{C}$ alloy thin films grown by PECVD are slightly p-type, i.e. essentially intrinsic $[1,3,4]$. In order to develop true boron-carbon homojunction devices, it is necessary to develop n-type materials by means of doping. The doping of boron-carbon alloys has only recently been examined [17], whereas the doping of crystalline boron-rich materials has been more extensively studied. In particular, $\beta$-rhombohedral boron, a p-type material, has been doped with $\mathrm{Mn}$, $\mathrm{P}$, and $\mathrm{Fe}[18-20]$, where only the latter was found to transform the material to n-type. Even though $\mathrm{Mn}$ and Fe have the same number of electrons in their outer shell $\left(4 s^{2}\right)$, they yield $\mathrm{p}$-and $\mathrm{n}$-type materials, which suggests that they may have markedly different structures. Attempts to dope crystalline boron carbide with $\mathrm{Si}\left(\mathrm{B}_{4.3} \mathrm{C}\right)$ and $\mathrm{P}\left(\mathrm{B}_{10} \mathrm{C}\right)$ failed to transform the material to n-type [21, 22]. These examples demonstrate the complexity of introducing dopants into boron-rich materials in order to obtain n-type character.

In this paper we present the results of $\mathrm{Ni}$ and $\mathrm{P}$ doping of boron-carbon alloy $\left(\mathrm{B}_{5} \mathrm{C}\right)$ thin films grown by PECVD. Transport, device characterization, and spectroscopic studies 
have been undertaken. This study demonstrates that the alloy polytypes of boron carbide exhibit behavior with doping similar to that observed for the single-crystal forms of $\beta$ rhombohedral boron and boron carbide even though the two forms have different transport properties.

\section{Growth and experimental details}

Boron-carbon alloy thin films were deposited on n-type $\mathrm{Si}(111)$ substrates following procedures described in detail elsewhere $[1,4,8,23]$. Deposition of the films was performed in a custom-designed parallel plate $13.56 \mathrm{MHz}$ radio-frequency PECVD reactor used in previous studies [1, $4,23]$. The silicon substrates were $n$-type doped to $7 \times 10^{14}$ / $\mathrm{cm}^{3}$. They were chemically etched and cleaned prior to insertion in vacuo and set on the lower electrode in the PECVD chamber. The substrates were further cleaned by $\mathrm{Ar}+$ bombardment at 300 mTorr, $40 \mathrm{~W}$ and annealed at $400{ }^{\circ} \mathrm{C}$ in the vacuum system. During deposition the samples were maintained at ground potential and the anode biased at $10 \mathrm{~V}$. The plasma power was $30 \mathrm{~W}$ and the chamber pressure was 400 mTorr.

The molecule closo-1,2-dicarbadodecaborane (orthocarborane) (see Fig. 1a) was used as the source compound for growing the boron-carbon alloy films. Nickelocene $\left(\mathrm{Ni}\left(\mathrm{C}_{5} \mathrm{H}_{5}\right)_{2}\right)$ was used as the nickel source. Nickelocene was introduced into the plasma reactor simultaneously with orthocarborane (closo-1,2-dicarbadodecaborane $\left(\mathrm{C}_{2} \mathrm{~B}_{10} \mathrm{H}_{12}\right)$ ). The orthocarborane partial pressure was $100 \mathrm{mTorr}$ and the nickelocene partial pressure ranged from 50 mTorr (low doping) to $150 \mathrm{mTorr}$ (high doping). An estimation of a Ni doping concentration of $>>1 \times 10^{21}$ has been determined based on the Ni spectral lines in Auger electron spectroscopy (AES) and X-ray emission spectroscopy (XES). Subsequent lower doping levels, i.e. lower nickelocene partial pressures, have been estimated based on the assumption that the level of $\mathrm{Ni}$ incorporation is proportional to the nickelocene partial pressure during deposition. The boron-carbon alloy films were typically $2000-2500 \AA$ thick.

The boron-carbon-phosphorous or phosphorous-doped boron-carbon alloys were grown under the same conditions as the undoped boron-carbon alloys, except that a singlesource compound dimeric chloro-phospha(111)-carborane $\left(\left[\mathrm{C}_{2} \mathrm{~B}_{10} \mathrm{H}_{10} \mathrm{PCl}\right]_{2}\right)$ (see Fig. 1b) was used in place of orthocarborane. These phosphorus-doped films were typically $\geq 1$ $\mu \mathrm{m}$ thick. The optical gap of the P-doped boron-carbon alloy was measured using a double beam, double monochromator, Perkin-Elmer Lamda-9 series spectrophotometer. All $\mathrm{X}$-ray diffraction data were obtained using $\mathrm{Cu} K_{\alpha}$ radiation $(\lambda=1.54 \AA)$. Infrared absorption spectra have been obtained for undoped, Ni-doped, and phosphorus-doped boron-carbon alloys. The experimental details have been discussed in greater depth elsewhere [2].

Gold pads were sputtered onto the boron-carbon films and the rear of the Si substrates for diode device characterization. Wire contacts were attached to the gold pads with silver paste. This resulted in good ohmic contacts. The conductivity measurements were obtained using the standard four-point-probe method.

\section{Results}

\subsection{Structure and stoichiometry}

2.1.1 Ni- $\mathrm{B}_{5} \mathrm{C}_{1+\delta}$. Doping of the boron-carbon alloy films with $\mathrm{Ni}$ was achieved by introducing nickelocene into the growth chamber during deposition. Since nickelocene has two cyclopentadiene rings which contain $\mathrm{C}$ atoms, we have made the assumption that fragments of these rings are incorporated into the film. Therefore, we will henceforth represent the $\mathrm{Ni}$-doped boron-carbon alloy films as $\mathrm{Ni}-\mathrm{B}_{5} \mathrm{C}_{1+\delta}$, where $\delta$ is a fractional amount of carbon introduced into the film from the fragmentation of the cyclopentadiene rings [24]. The higher concentration of $\mathrm{C}$ may decrease the band gap, but should not change the intrinsic properties of the material [1]. The inclusion of $\mathrm{Ni}$ in the boron-carbon alloy films was verified with Auger electron spectroscopy (AES). The signature of $\mathrm{Ni}$ in the Auger spectra suggests that the Ni uptake is large and therefore these films are highly doped $(>>1$ $\times 10^{21}$ ).

In Fig. 2a we present infrared (IR) absorption spectra of an undoped $\mathrm{B}_{5} \mathrm{C}$ film and a 'low'-doped $\mathrm{Ni}-\mathrm{B}_{5} \mathrm{C}_{1+\delta}$ film. Similar IR spectra were obtained for the boron-carbon films with 'high' Ni doping. The spectra in Fig. 2a are comparable to absorption spectra obtained by Shirai et al. [25] for boroncarbon alloys. For both $\mathrm{B}_{5} \mathrm{C}$ and $\mathrm{Ni}-\mathrm{B}_{5} \mathrm{C}_{1+\delta}$ strong vibration modes are observed between $900 \mathrm{~cm}^{-1}$ and $1500 \mathrm{~cm}^{-1}$. The mode at $942 \mathrm{~cm}^{-1}$ is attributed to B-B vibrational modes of the boron network. We have tentatively assigned the continuum of states between $1100-1500 \mathrm{~cm}^{-1}$ to $\mathrm{B}-\mathrm{C}$ vibrational

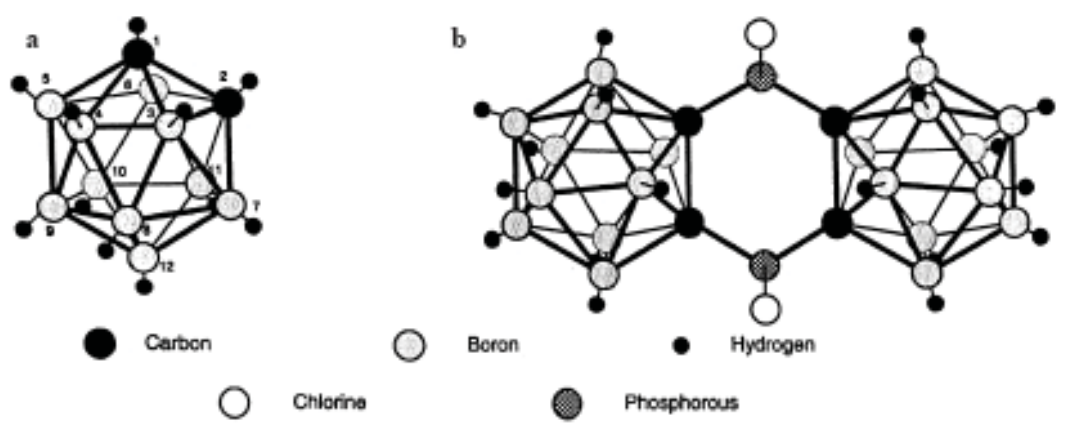

Fig. 1a,b. Schematic diagrams of the source molecules a orthocarborane $\left(\mathrm{C}_{2} \mathrm{~B}_{1} \mathrm{OH}_{12}\right)$ and $\mathbf{b}$ dimeric chloro-phospha(III)carborane $\left(\left[\mathrm{C}_{2} \mathrm{~B}_{10} \mathrm{H}_{10} \mathrm{PCl}\right]_{2}\right)$ 


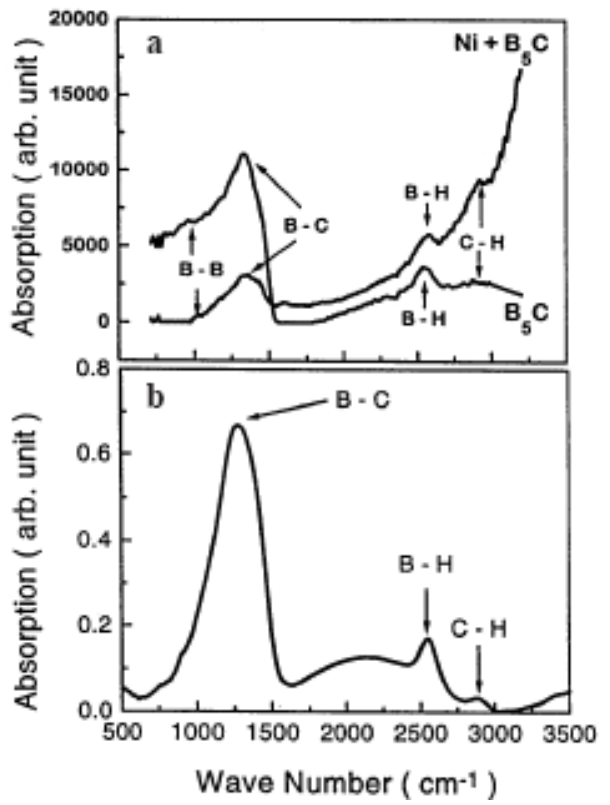

Fig. 2a,b. IR adsorption spectra of: $\mathrm{a}_{5} \mathrm{C}$ film and a 'low'-doped $\mathrm{Ni}-\mathrm{B}_{5} \mathrm{C}_{1+\delta}$ film, and $\mathbf{b}$ a phosphorus-doped $\mathrm{B}_{5} \mathrm{C}$ film

modes. A B-H mode is observed at $2535 \mathrm{~cm}^{-1}$ and is indicative of the inclusion of $\mathrm{H}$. The IR absorption spectrum of the $\mathrm{Ni}-\mathrm{B}_{5} \mathrm{C}_{1+\delta}$ film in Fig. 2a shows a dramatic decrease in the intensity of the B-B and B-C modes. The introduction of defects with Fe doping has been attributed to the dampening of vibrational modes of Fe-doped single-crystal boron carbide [18]. This argument may apply to these $\mathrm{Ni}-\mathrm{B}_{5} \mathrm{C}_{1+\delta}$ films.

$\mathrm{X}$-ray diffraction measurements of the $\mathrm{Ni}-\mathrm{B}_{5} \mathrm{C}_{1+\delta}$ films were essentially equivalent to those of undoped $\mathrm{B}_{5} \mathrm{C}$ [1] (see Fig. 3b), although, we do anticipate a high defect density with $\mathrm{Ni}$ doping in light of the attenuation in the $900-1500 \mathrm{~cm}^{-1}$ modes in the absorption spectrum of $\mathrm{Ni}-\mathrm{B}_{5} \mathrm{C}_{1+\delta}$ (Fig. 2a). More detailed structural measurements will need to be performed to determine the detailed changes due to Ni doping.

2.1.2 Phosphorus-doped $\mathrm{B}_{5} \mathrm{C}$. In Fig. $2 \mathrm{~b}$ we present the IR absorption spectrum for phosphorus-doped $\mathrm{B}_{5} \mathrm{C}$. The spectrum is very similar to that for the undoped material. Again, the continuum of states from $1100-1500 \mathrm{~cm}^{-1}$ are B-C vibrational modes, the state at $2535 \mathrm{~cm}^{-1}$ is the $\mathrm{B}-\mathrm{H}$ mode, and the $\mathrm{C}-\mathrm{H}$ mode is at $2916 \mathrm{~cm}^{-1}$. Unlike the Ni-doped alloy, the intensity of the $\mathrm{B}-\mathrm{C}$ modes remains quite strong. In addition, the background is much less for the P-doped alloy, compared to that for the Ni-doped alloy.

$\mathrm{X}$-ray emission from phosphorus is very low and indicates that there is very little phosphorus content in the PECVD-grown $\mathrm{P}-\mathrm{B}_{5} \mathrm{C}$ films ( $\left.\ll 3 \%\right)$. Consequently, these $\mathrm{P}-\mathrm{B}_{5} \mathrm{C}$ films are more akin to a phosphorus-doped $\mathrm{B}_{5} \mathrm{C}$ alloy rather than a ternary $\mathrm{P}-\mathrm{B}-\mathrm{C}$ alloy. In Fig. 3 we present the $\mathrm{X}$-ray diffraction pattern for the $2 \theta$ range from $20^{\circ}$ to $60^{\circ}$ of (a) a $\mathrm{P}$-doped $\mathrm{B}_{5} \mathrm{C}$ film approximately $1 \mu \mathrm{m}$ thick and (b) a $2500-\AA$-thick $\mathrm{B}_{5} \mathrm{C}$ film. The strong sharp peaks are the $\mathrm{Si}\langle 111\rangle$ and $\langle 222\rangle$ diffraction lines. A single broad diffrac-
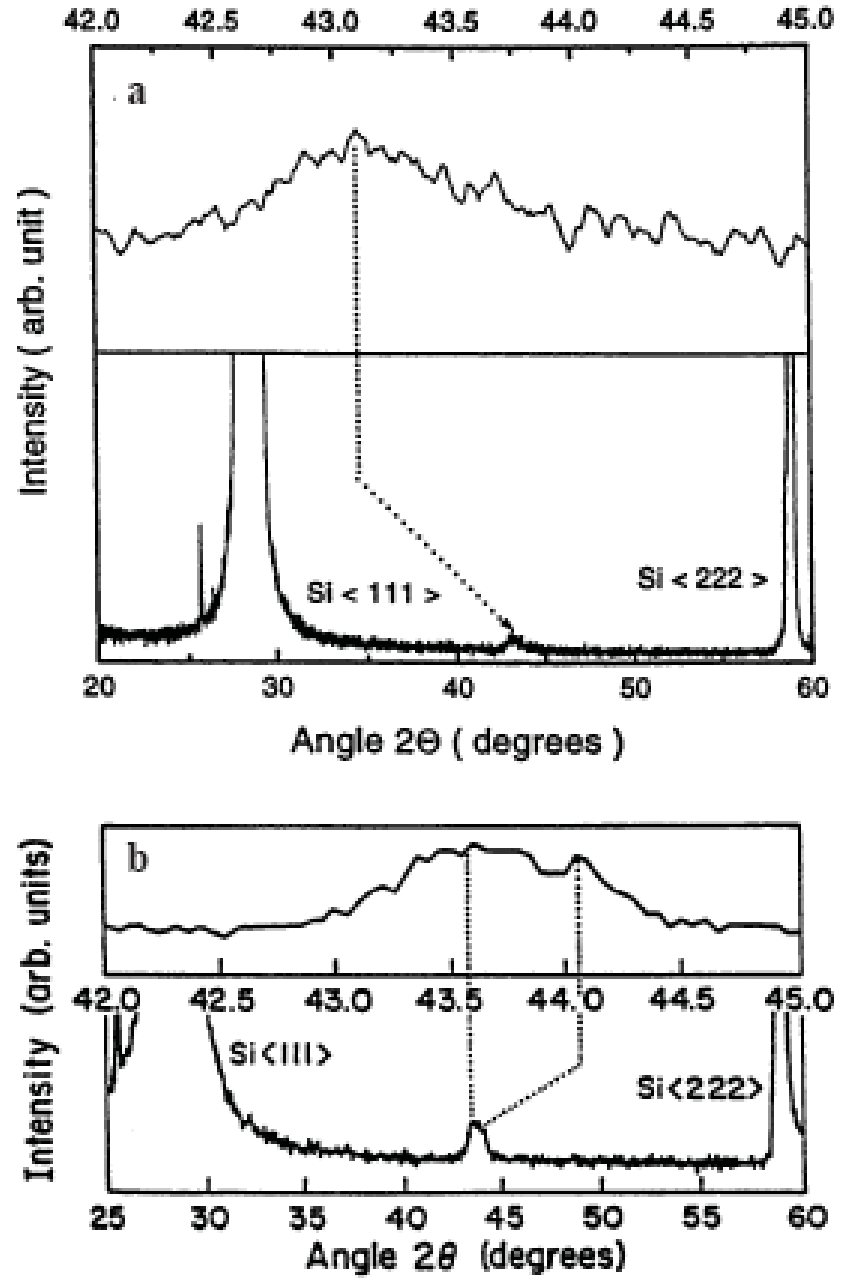

Fig. 3a,b. X-ray diffraction patterns of: a phosphorus-doped $\mathrm{B}_{5} \mathrm{C}$, and $\mathbf{b}$ undoped $\mathrm{B}_{5} \mathrm{C}$, both grown on $\mathrm{Si}(111)$, in the $2 \theta$ range from $20^{\circ}$ to $60^{\circ}$. The large sharp peaks are the $\mathrm{Si}\langle 111\rangle$ and $\mathrm{Si}\langle 222\rangle$ diffraction lines

ture is $2.10 \AA$. In contrast, a double diffraction peak at $43.7^{\circ}$ and $44.2^{\circ}$ is observed in Fig. $3 \mathrm{~b}$ for undoped $\mathrm{B}_{5} \mathrm{C}[1,8,27]$. The calculated $\mathrm{d}$ spacing for the doublet diffraction peak is $2.03 \AA$ and $1.87 \AA$, respectively, which is $5 \%-10 \%$ smaller than for the P-doped alloy. The spacings of the P-doped and undoped $\mathrm{B}_{5} \mathrm{C}$ alloys are smaller than the $2.74 \AA$ spacing reported for single-crystal $\mathrm{B}_{7} \mathrm{C}[28,29]$. The average grain size of the phosphorus-doped alloy is approximately $57 \AA$, compared to approximately $100 \AA$ for the undoped $\mathrm{B}_{5} \mathrm{C}$ film. We speculate that the diffraction pattern and smaller grain size of the $\mathrm{P}$-doped $\mathrm{B}_{5} \mathrm{C}$ may be indicative of a new polytype [30].

\subsection{Transport and electronic structure}

2.2.1 Nickel-doped $\mathrm{B}_{5} \mathrm{C}_{1+\delta}$. The inclusion of $\mathrm{Ni}$ in $\mathrm{B}_{5} \mathrm{C}$ dramatically increases the conductivity by approximately eight orders of magnitude from $10^{-9}(\Omega \mathrm{cm})^{-1}$ at room temperature for undoped $\mathrm{B}_{5} \mathrm{C}$ to $6.67 \times 10^{-3}(\Omega \mathrm{cm})^{-1}$. Similar in- 
creases in the conductivity with carbon doping of boron-rich solids have been observed [31]. In Fig. 4 we have plotted the conductivity of $\mathrm{Ni}-\mathrm{B}_{5} \mathrm{C}_{1+\delta}$ for a low nickel concentration $(<$ $\left.1 \times 10^{19}\right)$, as determined from the spectral intensity of the $\mathrm{Ni}$ feature in the corresponding Auger spectrum) as a function of the reciprocal temperature. The linear region of the conductivity in Fig. 4 has been fitted to the Arrhenius relationship,

$$
\ln \sigma=\ln \sigma_{0}-E_{\mathrm{A}} / k_{\mathrm{B}} T,
$$

where $\sigma_{0}$ is the initial conductivity, $E_{\mathrm{A}}$ is the thermal activation energy, $k_{\mathrm{B}}$ is Boltzman's constant, and $T$ is the temperature. This gives an apparent activation energy of $0.200 \mathrm{eV}$, which is much less than the $1.25 \mathrm{eV}$ value obtained for undoped $\mathrm{B}_{5} \mathrm{C}$ [1]. Werheit et al. [32] found evidence of states pinned approximately $200 \mathrm{meV}$ below the conduction edge. Our data for the Ni-doped boron-carbon alloy also suggest the presence of donor states approximately $200 \mathrm{meV}$ below the conduction band edge.

The I-V curves of two diodes constructed with $\mathrm{Ni}-\mathrm{B}_{5} \mathrm{C}_{1+\delta}$ grown on n-type $\mathrm{Si}(111)$ are displayed in panels (b) and (c) in Fig. 5. When compared to the diode constructed with $\mathrm{B}_{5} \mathrm{C}$ (Fig. 5a), the results in Figs. 5b and 5c indicate that Ni doping transforms $\mathrm{B}_{5} \mathrm{C}$ from $\mathrm{p}$-type to n-type. These diodes rectify with reverse bias, i.e. the nickel-doped boron-carbon alloy appears n-type relative to the lightly doped n-type silicon substrate.

With the 'high' nickel doping, a negative differential resistance, or a valley in the current, occurs in the effective forward bias direction for diodes formed on n-type silicon, as well as on p-type $\mathrm{Si}$, as seen in Fig. 5c. This behavior is characteristic of a tunnel diode [33-41] and is consistent with degenerative doping and the introduction of donor states below the conduction band minimum.

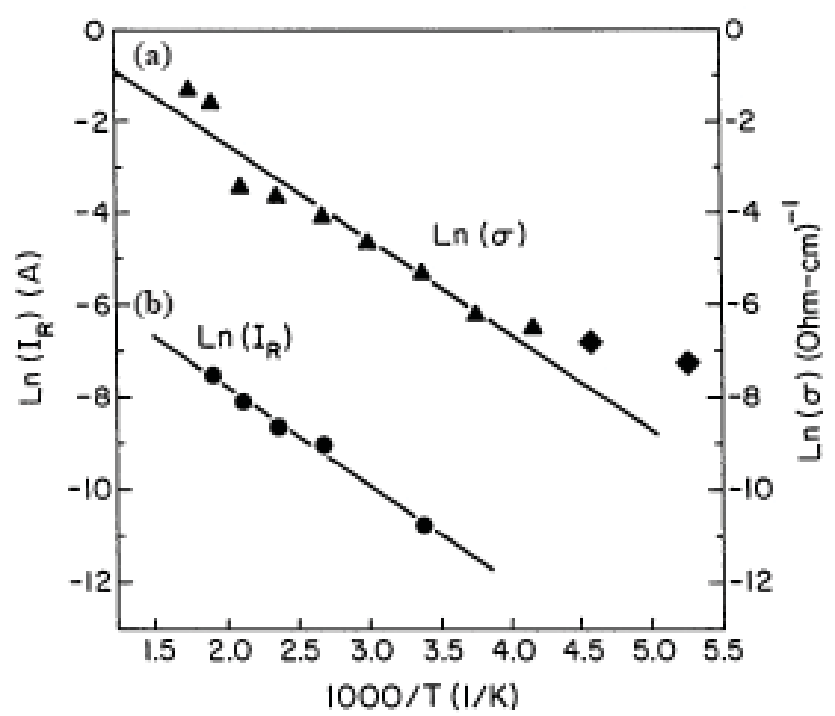

Fig. 4 (a) The natural $\log$ of the conductivity of $\mathrm{Ni}-\mathrm{B}_{5} \mathrm{C}_{1+\delta}$ as a function of reciprocal temperature, where the line is a fit of the data, and (b) the natural $\log$ of the leakage current of a Ni- $\mathrm{B}_{5} \mathrm{C}_{1+\delta} / \mathrm{B}_{5} \mathrm{C}$ diode as a function of reciprocal temperature
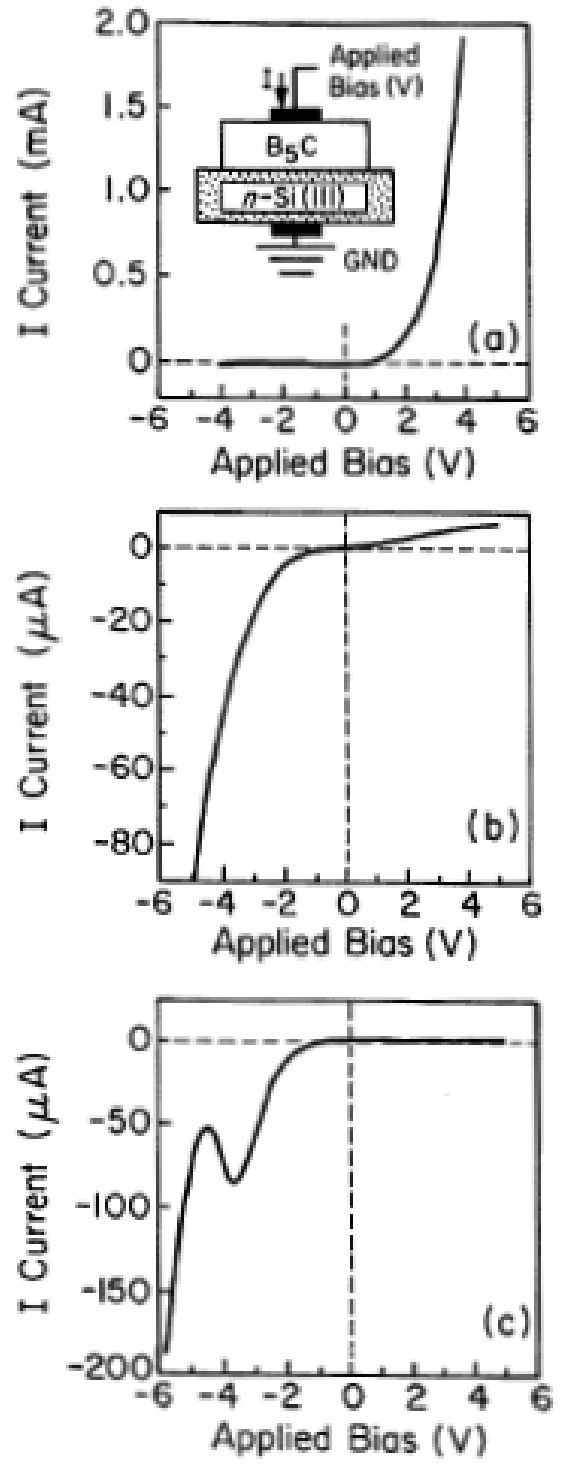

Fig. 5a-c. The diode $I-V$ characteristics of a $\mathrm{B}_{5} \mathrm{C} / \mathrm{n}-\mathrm{Si}(111), \mathbf{b} \mathrm{Ni}-\mathrm{B}_{5} \mathrm{C}_{1+\delta} /$ $\mathrm{n}-\mathrm{Si}(111)$ with a 'low' nickel concentration, and $\mathbf{c}$ the $I-V$ curve of a tunnel diode of $\mathrm{Ni}-\mathrm{B}_{5} \mathrm{C}_{1+\delta} / \mathrm{n}-\mathrm{Si}(111)$ with a 'high' nickel concentration. The inset in a is a schematic of the $\mathrm{B}_{5} \mathrm{C} / \mathrm{n}-\mathrm{Si}(111)$ diode

In Fig. 6 we present one of the few homojunction diode ever constructed exclusively with boron-carbon thin films [24]. The diode was constructed by growing p-type $\mathrm{B}_{5} \mathrm{C}$ on n-type $\mathrm{Ni}-\mathrm{B}_{5} \mathrm{C}_{1+\delta}$. The temperature dependence of the rectifying properties of the diode is also displayed in Fig. 6. For temperatures exceeding $500 \mathrm{~K}$, the leakage current increases by less than $1 \mathrm{~mA}$ at $-4 \mathrm{~V}$. The temperature dependence of this homojunction diode is much less significant than for earlier $\mathrm{B}_{5} \mathrm{C} / \mathrm{n}$-type $\mathrm{Si}(111)$ heterojunction diodes [4]. The natural $\log$ of the leakage current $\left(I_{R}\right)$ as a function of reciprocal temperature is plotted in Fig. 4. A fit of the data gives an activation barrier height of $200 \mathrm{meV}$.

This activation barrier is dependent on the nickel doping level. In Fig. 7 we have plotted the activation barrier, determined from the leakage current, as a function of nickelocene partial pressure during deposition. Assuming that the Ni uptake 


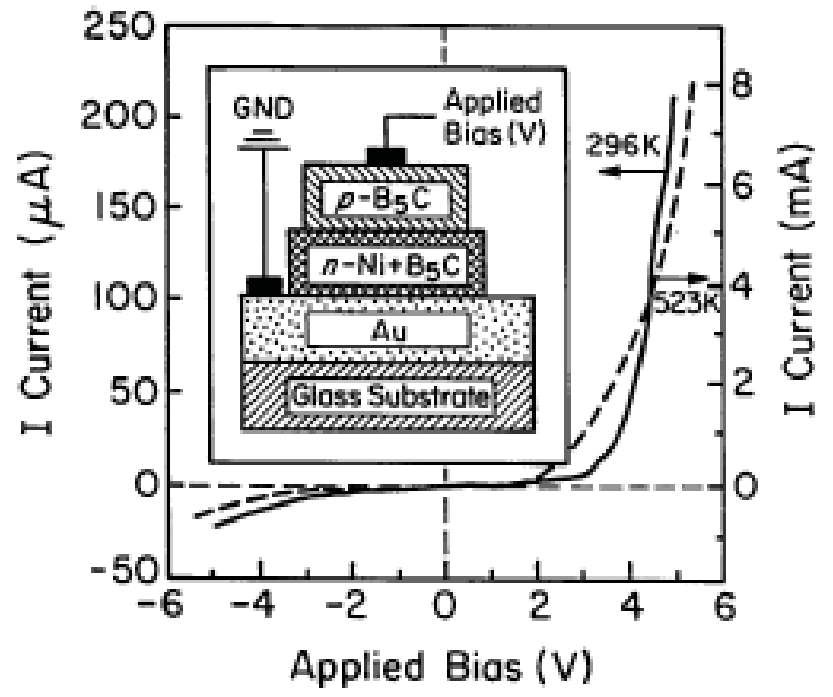

Fig. 6. The $I-V$ curve of a $\mathrm{Ni}-\mathrm{B}_{5} \mathrm{C}_{1+\delta} / \mathrm{B}_{5} \mathrm{C}$ diode with a 'low' Ni concentration at temperatures of $296 \mathrm{~K}$ and $523 \mathrm{~K}$. The inset is a schematic of the diode construction

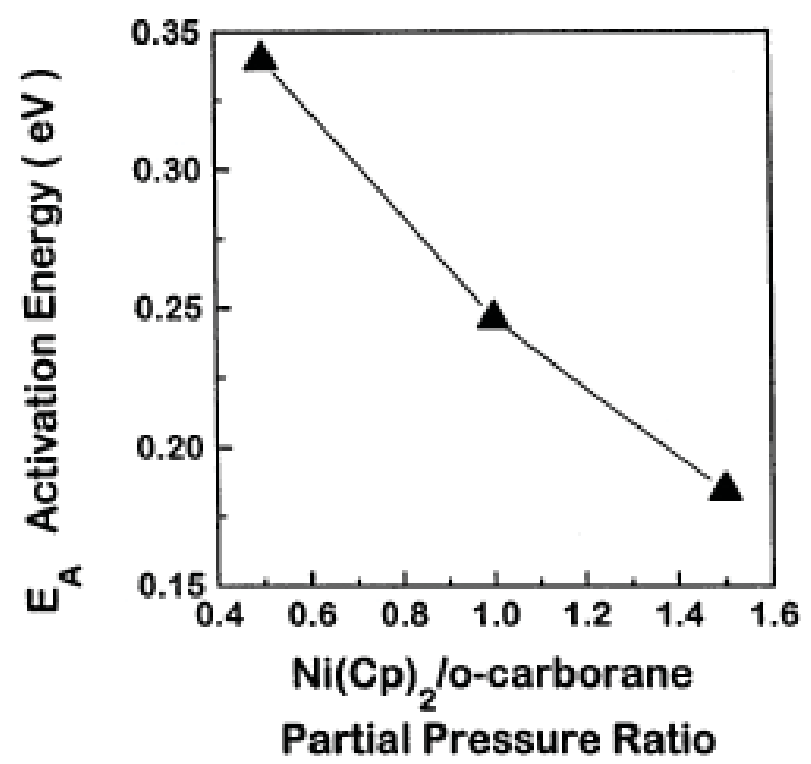

Fig. 7. The activation barrier of $\mathrm{Ni}-\mathrm{B}_{5} \mathrm{C}_{1+\beta} / \mathrm{B}_{5} \mathrm{C}$ homojunction diodes as a function of nickelocene partial pressure during film deposition

into the film is proportional to the nickelocene partial pressure, the results of Fig. 7 indicate that the density of states introduced into the gap increases with $\mathrm{Ni}$ concentration.

2.2.2 Phosphorus-doped $\mathrm{B}_{5} \mathrm{C}$. The conductivity of the phosphorus-doped boron-carbon alloy is $1.47 \times 10^{-11}(\Omega \mathrm{cm})^{-1}$ [30]. This is approximately two orders of magnitude less than the conductivity of undoped $\mathrm{B}_{5} \mathrm{C}$ alloy [1]. This suggests that, like the undoped material, the phosphorus-doped alloy is also a near-perfectly compensated material with very few carriers. The optical gap of the phosphorus-doped B5C alloy has been determined by plotting $(\alpha E)^{1 / 2}$ versus energy (E), as seen in Fig. 8. From the standard Tauc plot [42], the band gap has been determined to be $2.6 \mathrm{eV}$. This value is more consistent with the band gap of $\mathrm{B}_{12} \mathrm{P}$ [43] than for undoped PECVDgrown $\mathrm{B}_{5} \mathrm{C}$ which has a band gap of typically between 0.7 and

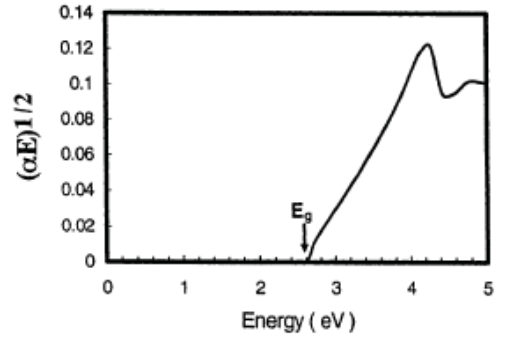

Fig. 8. The Tauc plot of a phosphorus-doped boron-carbon alloy thin film $\left(\mathrm{P}-\mathrm{B}_{5} \mathrm{C}\right) . E_{\mathrm{g}}$ identifies the position of the band gap at $2.6 \mathrm{eV}$

$0.9 \mathrm{eV}[1,2]$. In contrast to the single-crystal material, the concentration of phosphorus in the $\mathrm{B}_{5} \mathrm{C}$ alloy is $\ll 3 \%$.

\section{Discussion}

It is the icosahedral network of the boron-carbon alloys which gives them their unique transport properties. Consequently, the introduction of dopants can have dramatic effects on their transport. In order to understand fully how the different dopants may affect bulk transport, it is important to understand how dopants are accommodated within the icosahedral network. Dopants can be introduced into the icosahedral network either by substitution or by network modification. The effects of the two pathways are as yet unclear. Through the correlation of the structural and stoichiometric properties with transport properties, this issue may be resolved.

\subsection{Structure and stoichiometry}

3.1.1 Nickel-doped $\mathrm{B}_{5} \mathrm{C}_{1+\delta}$. $\mathrm{X}$-ray diffraction indicates that the structure of $\mathrm{B}_{5} \mathrm{C}$ and $\mathrm{Ni}-\mathrm{B}_{5} \mathrm{C}_{1+\delta}$ appear to be equivalent. This is consistent with studies of Fe-doped single crystals of $\beta$-rhombohedral boron where the Fe atoms filled in voids rather than displacing boron atoms within the lattice [18, 44]. Kuhlmann et al. [18, 44] found that even at an Fe concentration as large as $4 \%$, the unit cell of $\beta$-rhombohedral boron increased by less than $0.5 \%$. The lack of any apparent change in the crystal structure of $\mathrm{Ni}-\mathrm{B}_{5} \mathrm{C}_{1+\delta}$ is consistent with crystallographic studies of $\mathrm{Fe}$-doped $\beta$-rhombohedral boron.

The filling of voids with Fe doping of $\beta$-rhombohedral boron has been attributed to the dampening of vibrational modes in IR absorption spectra in the $150-600 \mathrm{~cm}^{-1}$ range [18, 44]. In the IR absorption spectrum of $\mathrm{Ni}^{-} \mathrm{B}_{5} \mathrm{C}_{1+\delta}$ in Fig. $2 \mathrm{a}$ we see that there is significant dampening of vibrational modes below $1500 \mathrm{~cm}^{-1}$, which includes the B-C modes between 1100 $1500 \mathrm{~cm}^{-1}$. The B-C modes are either icosahedral breathing modes or B-C chain-stretching modes. The dampening of modes below $1500 \mathrm{~cm}^{-1}$, can be explained in either of two ways. The first is that $\mathrm{Ni}$ is incorporated into the voids in the icosahedral network. The alternative explanation is that $\mathrm{Ni}$ alters the symmetry at the sites of inclusion such that these modes are no longer allowed. Both explanations are consistent with the X-ray diffraction of $\mathrm{Ni}-\mathrm{B}_{5} \mathrm{Cl}_{+\delta}$ which indicated that the icosahedral crystalline network structure of $\mathrm{B}_{5} \mathrm{C}$ remains intact with Ni doping. Subtraction of a smooth background from the $\mathrm{Ni}-\mathrm{B}_{5} \mathrm{C}_{1+\delta}$ IR spectrum indicates that the concentra- 
tion of $\mathrm{H}$ in the boron- carbon alloy does not significantly increase with Ni doping. This is an important issue since the incorporation of excess hydrogen could passivate the Ni donor states and leave the material p-type.

3.1.2 Phosphorus-doped $\mathrm{B}_{5} \mathrm{C}$. In contrast to $\mathrm{Ni}$ doping, the broad diffraction peak in Fig. 3a of P-doped $\mathrm{B}_{5} \mathrm{C}$ indicates that the inclusion of phosphorus does modify the structure of the boron-carbon alloy. This suggests that phosphorus cannot simply go into voids in the icosahedral network, but probably substitutes into the network. This is consistent with phosphorus doping of single-crystal boron carbide and $\beta$-rhombohedral boron $[20,22]$. In both of these systems, phosphorus is substituted for $\mathrm{C}$ or $\mathrm{B}$ sites in the diagonal chains which connect the icosahedral network. The larger covalent radii of $\mathrm{P}$, relative to B and C, may subsequently distort the lattice and explain the change observed in the X-ray diffraction pattern of the P-doped material in Fig. 3a. This is consistent with observed lattice distortions of single-crystal $\mathrm{B}_{1-x} \mathrm{C}_{x}$ when the $\mathrm{C}$ concentration exceeds $20 \%$ [31, 32]. Chain vacancies as large as $25 \%$ are expected for single-crystal boron carbide [16].

We expect the density of chain vacancies to be higher in the alloys than in the single-crystal materials, because of the short-range order of the boron-carbon alloys. Subsequently, if the dominant mechanism for P incorporation is by substitution, then a reduction in chain sites will greatly inhibit the fractional amount of phosphorus introduced into the boroncarbon alloy. This is substantiated by an X-ray emission line for phosphorus, that at best is very weak compared to the Auger signal observed for $\mathrm{Ni}-\mathrm{B}_{5} \mathrm{C}_{1+\delta}$.

The IR absorption spectrum of the P-doped alloy in Fig. $2 \mathrm{~b}$ exhibits the same general structure as the spectrum for undoped $\mathrm{B}_{5} \mathrm{C}$. The $\mathrm{B}-\mathrm{C}$ vibrational modes between 1100 and $1500 \mathrm{~cm}^{-1}$ of the $\mathrm{P}$-doped material are still quite strong, in contrast to the spectrum of $\mathrm{Ni}-\mathrm{B}_{5} \mathrm{C}_{1+\delta}$. The large background above $2500 \mathrm{~cm}^{-1}$ observed for the Ni-doped alloy is also absent from the P-doped material. Common to all these alloy materials are the $\mathrm{B}-\mathrm{H}$ and $\mathrm{C}-\mathrm{H}$ vibrational modes at 2535 and $2916 \mathrm{~cm}^{-1}$, respectively. The strong similarities between the P-doped and undoped boron-carbon alloys, in conjunction with the striking differences from the Ni-doped material, argues strongly in favor of phosphorus substitution rather than the filling of voids, as appears to be the case for Ni-doping. Substitution of phosphorus for C or B atoms in the chains would shift the $\mathrm{B}-\mathrm{C}$ vibrational modes, but would neither attenuate nor modify the symmetries of these modes. The IR spectra also substantiate the observed differences between the two doped materials with X-ray diffraction. These differences should be manifested in the electronic properties of the doped materials.

\subsection{Conductivity of nickel-doped $B_{5} C_{1+\delta}$ and phosphorus-doped $B_{5} C$}

The conductivity of $\mathrm{B}_{5} \mathrm{C}$, similar to that of $\beta$-rhombohedral boron, increases with the introduction of select dopants. In the case of Ni doping, the conductivity increases from 10-9
$(\Omega \mathrm{cm})^{-1}$ for undoped films to $6.67 \times 10^{-3}(\Omega \mathrm{cm})^{-1}$ at room temperature. Similarly, the conductivity of iron-doped $\beta$ rhombohedral boron increased by approximately three orders of magnitude from $1 \times 10^{-3}(\Omega \mathrm{cm})^{-1}$ to approximately $1(\Omega$ $\mathrm{cm})^{-1}$ at room temperature [19]. The conduction mechanism of $\mathrm{Ni}-\mathrm{B}_{5} \mathrm{C}_{1+\delta}$ can be broken down into two regimes: a hightemperature regime where the conductivity obeys the Arrhenius relationship and a low-temperature regime where the conduction is better described in terms of a hopping mechanism. This is apparent from the deviation of the linear dependence of the conductivity at low temperatures in Fig. 4. Similar behavior has been observed for single-crystal boron carbide [22] and amorphous silicon carbide [45]. This is in contrast to Fe-doped $\beta$-rhombohedral boron where the transport was found to obey Mott's law $\sigma=\sigma_{0} \exp \left(T_{0} / T\right)^{1 / 4}$ for variable range hopping over a large range of temperatures [19]. While the conduction mechanisms of $\mathrm{Ni}-\mathrm{B}_{5} \mathrm{C}_{1+\delta}$ and Fe-doped $\beta$-rhombohedral boron appear to be different, the fact that the conductivity of both of these undoped materials increases with doping supports our earlier conjecture that $\mathrm{Ni}$ atoms go into voids in the icosahedral network.

A fit of the linear region in Fig. 4 yields an activation energy of $0.200 \mathrm{eV}$. This is significantly lower than the activation energy of $1.25 \mathrm{eV}$ for undoped $\mathrm{B}_{5} \mathrm{C}$ [1], but it is comparable to activation energies of single-crystal boron carbide $(140-160 \mathrm{meV})[9,46]$, and phosphorus-doped $\beta$-rhombohedral boron (220-240 meV) [22]. The dramatic decrease in the activation energy of the boron-carbon alloy with nickel doping indicates that additional states are introduced into the gap. Using optical techniques, Werheit et al. have observed such states for Fe-doped $\beta$-rhombohedral boron [32], Si-doped $\beta$-rhombohedral boron [21], and $\mathrm{MgAlB}_{14}$-type borides [32]. The large background beginning at approximately $2700 \mathrm{~cm}^{-1}$ in the IR spectrum of $\mathrm{Ni}^{-} \mathrm{B}_{5} \mathrm{C}_{1+\delta}$ (Fig. 2a) is indicative of new optically allowed transitions and supports our conclusion that Ni doping introduces states into the gap. Since Ni doping (as discussed in more detail in the next section) of $\mathrm{B}_{5} \mathrm{C}$ leads to an n-type material, we can now explain the origin of the increased background absorbance above approximately $1800 \mathrm{~cm}^{-1}$ in Fig. 2. Since donor states are approximately $200 \mathrm{meV}$ below the conduction band edge, optical transitions at about $1600 \mathrm{~cm}^{-1}$ and higher are possible from the donor states to the conduction band continuum, i.e. the greater the energy of the radiation, the greater the absorption efficiency. The introduction of donor states with Ni doping clearly adds charge carriers. This leads to a decline in the resistivity with increased doping. The increase in the number of charge carriers also has the effect of decreasing the thermal activation barrier, as seen in Fig. 7. This is the type of behavior one would anticipate.

The reduced conductivity of phosphorus-doped $\mathrm{B}_{5} \mathrm{C}$ (from $1 \times 10^{-9}(\Omega \mathrm{cm})^{-1}$ to $1.47 \times 10^{-11}(\Omega \mathrm{cm})^{-1}$ ) is consistent with phosphorus doping of $\beta$-rhombohedral boron [20] and boron carbide [22], where reductions in the conductivity of approximately two orders of magnitude were observed. If phosphorus were incorporated into the voids in a manner similar to that postulated for $\mathrm{Ni}$, we would anticipate an in- 
creased conductivity, contrary to our results. The incorporation of phosphorus substitutionally with strong covalent bonds will tend to localize the extra electron of phosphorus, relative to $\mathrm{B}$ and $\mathrm{C}$, more efficiently than is anticipated with the filling of voids. These results and the change in X-ray diffraction of $\mathrm{B}_{5} \mathrm{C}$ with phosphorus doping supports the interpretation that phosphorus is substitutionally incorporated into the icosahedral network. This is consistent with similar findings for phosphorus doping of $\beta$-rhombohedral boron, where phosphorus is substitutionally incorporated into the chain positions connecting the icosahedral network [20].

The effects of P-doping of $\mathrm{B}_{5} \mathrm{C}$ are dramatically illustrated in the Tauc plot in Fig. 8, which indicates that the band gap of phosphorus-doped $\mathrm{B}_{5} \mathrm{C}$ is $2.6 \mathrm{eV}$. This is an increase of approximately $1.7 \mathrm{eV}$ relative to the undoped material. The increased band gap of phosphorus-doped $\mathrm{B}_{5} \mathrm{C}$ is yet another example of the diverse effects that different dopants have on the electronic structure of the boron-carbon alloys. The 2.6eV-band gap with phosphorus doping lends further weight to our hypothesis that $\mathrm{Ni}$ is incorporated into the icosahedral network, possibly into chains connecting the icosahedra.

\subsection{Device properties of nickel-doped $B_{5} C_{1+\delta}$}

Heterojunction diodes constructed with $\mathrm{Ni}-\mathrm{B}_{5} \mathrm{C}_{1+\delta}$ thin films provide further insight into the changes to the $\mathrm{B}_{5} \mathrm{C}$ electronic structure with Ni-doping. The $I-V$ curve in Fig. 5 a of a diode constructed with undoped PECVD $\mathrm{B}_{5} \mathrm{C}$ alloy film on n-type Si demonstrates the p-type character of this material and has the expected rectifying character with forward bias. In contrast, the $I-V$ curve in Fig. $5 \mathrm{~b}$ of a Ni- $\mathrm{B}_{5} \mathrm{C}_{1+\delta}$ alloy film grown on n-type $\mathrm{Si}$ rectifies with reverse bias. This demonstrates that the Ni-doped material is an n-type semiconductor and that this forms an $\mathrm{n}^{+}-\mathrm{n}$ heterojunction, where $\mathrm{Ni}-\mathrm{B}_{5} \mathrm{C}_{1+\mathrm{d}}$ is more n-type than the $\mathrm{Si}$ substrate. The transformation of $\mathrm{B}_{5} \mathrm{C}$ with $\mathrm{Ni}$ doping agrees with studies of $\beta$ rhombohedral boron which changed from p-type to n-type with $\mathrm{Fe}$ doping $[18,19]$. The $\mathrm{n}$-type behavior of $\mathrm{B}_{5} \mathrm{C}$ with $\mathrm{Ni}$ doping is significant since $\mathrm{Fe}$ is the only previously known dopant to cause this type of transformation in a boron-rich material with icosahedral structure. Naively, one might reach the conclusion that all metal dopants will result in an n-type boron-rich material, yet studies of Mn doping of $\beta$-rhombohedral boron found that the material remained p-type [18].

The $I-V$ curve in Fig. $5 \mathrm{c}$ of a diode constructed with a highly doped $\left(\gg 1 \times 10^{21}\right) \mathrm{Ni}-\mathrm{B}_{5} \mathrm{C}_{1+\delta}$ alloy films exhibits a negative differential resistance, or a valley in the current, in the reverse bias direction and is characteristic of a tunnel diode. The tunneling behavior is due to Ni donor states just below the conduction band minimum. This is illustrated in the diagram of the electronic structure of $\mathrm{Ni}-\mathrm{B}_{5} \mathrm{C}_{1+\delta}$ in Fig. 9. The conductivity measurements of $\mathrm{Ni}-\mathrm{B}_{5} \mathrm{C}_{1+\delta}$ (see Fig. 4) position these states $200 \mathrm{meV}$ below the CBM. The tunneling of these states generates a current into the conduction band of $\mathrm{Ni}-\mathrm{B}_{5} \mathrm{C}_{1+\delta}$, which opposes the direction of the conduction electrons which flow from the $\mathrm{Ni}-\mathrm{B}_{5} \mathrm{C}_{1+\delta}$ alloy into

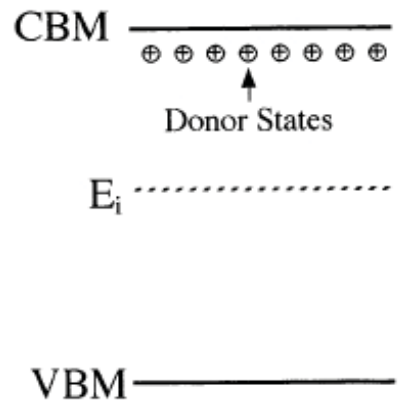

Fig. 9. Schematic energy band representations of donor states in the band gap of a semiconductor. $E_{\mathrm{i}}$ represents the Position of the Chemical potential in the gap for the intrinsic semiconductor materials.

the n-type $\mathrm{Si}$. At approximately $5 \mathrm{~V}$ the tunneling current is overwhelmed by the conduction current and normal diode behavior is established.

With the development of a PECVD process for growing n-type boron-carbon alloys, it is now possible to construct homojunction diodes using $\mathrm{B}_{5} \mathrm{C}$ and $\mathrm{Ni}-\mathrm{B}_{5} \mathrm{C}_{1+\delta}$. An example of the rectifying properties of such a device is displayed in Fig. 6. Note that the diode is in forward bias when the undoped, or p-type material, is positive with respect to the nickel-doped material. This conclusively demonstrates the ntype properties of the Ni-doped material. To the best of our knowledge, this is the first successful construction of a boron-based homojunction diode. The diode has very good rectifying properties with an onset voltage of approximately $3 \mathrm{~V}$ and a leakage current of less than $25 \mu \mathrm{A}$ at $-4 \mathrm{~V}$.

The rectifying properties of the homojunction diode at an elevated temperature are also displayed in Fig. 6. The onset voltage decreases systematically with increasing temperature and eventually reaches a value of approximately $1.5 \mathrm{~V}$ at $523 \mathrm{~K}$. However, the temperature dependence of the leakage current is very small and indicates that the tunneling effect is small and therefore these boron-carbon homojunction diodes should be stable against breakdown via tunneling. A fit of the temperature dependence of the leakage current gives an activation energy of $200 \mathrm{meV}$ for this Ni-doping level. This $\mathrm{B}_{5} \mathrm{C} / \mathrm{Ni}-\mathrm{B}_{5} \mathrm{C}_{1+\delta}$ homojunction diode is much more impervious to thermal breakdown than earlier $\mathrm{B}_{5} \mathrm{C} / \mathrm{n}$-type $\mathrm{Si}(111)$ heterojunction diodes [4] and demonstrates the need for n-type boron-carbon alloy thin films in order to further the development of high temperature boron-carbon devices.

\section{Summary}

We have examined the effects of phosphorus and nickel doping on the structural and electronic properties of boron- carbon alloys. X-ray diffraction studies indicate that the structure of the Ni-doped material is essentially unchanged from that of undoped $\mathrm{B}_{5} \mathrm{C}$. In contrast, a single broad diffraction peak is observed for the P-doped alloy, rather than the double diffraction peak of undoped $\mathrm{B}_{5} \mathrm{C}$. These results indicate that the boron-carbon alloy structure is dependent on the type of dopant. The structure of $\mathrm{Ni}-\mathrm{B}_{5} \mathrm{C}_{1+\delta}$ and $\mathrm{B}_{5} \mathrm{C}$ ap- 
pear similar, as are their vibration modes. Nonetheless, the low energy modes between $900-1500 \mathrm{~cm}^{-1}$ are dramatically suppressed with Ni doping, whereas absorption at higher energies $\left(>2700 \mathrm{~cm}^{-1}\right)$ increases significantly. Similarly, the absorption spectra of P-doped $\mathrm{B}_{5} \mathrm{C}$ is very similar to undoped $\mathrm{B}_{5} \mathrm{C}$. Based on the $\mathrm{X}$-ray diffraction and absorption spectroscopy, we have postulated that $\mathrm{Ni}$ is incorporated into voids in the icosahedral network, while $\mathrm{P}$ substitutes for B and $\mathrm{C}$ atoms in the icosahedral network. This issue, along with a better understanding of the microstructure in general, must be pursued.

The conductivity increased by six orders of magnitude with Ni doping and decreased by two orders of magnitude with $\mathrm{P}$ doping. The temperature-dependent conductivity of $\mathrm{Ni}-\mathrm{B}_{5} \mathrm{C}_{1+\delta}$ was found to obey the Arrhenius relationship. The activation energy of $200 \mathrm{meV}$ of moderately doped $\mathrm{Ni}-\mathrm{B}_{5} \mathrm{C}_{1+\delta}$ $(\gg 1021)$ indicates that new states are introduced just below the conduction band. We have argued that the increased conductivity with $\mathrm{Ni}$ doping is consistent with incorporation of $\mathrm{Ni}$ into voids in the icosahedral network and that the reduced conductivity with phosphorus doping is consistent with substitution into the boron-carbon icosahedral network.

Diodes constructed with $\mathrm{Ni}-\mathrm{B}_{5} \mathrm{C}_{1+\delta}$ thin films demonstrated that $\mathrm{Ni}$ doping transforms undoped $\mathrm{B}_{5} \mathrm{C}$ from an intrinsically p-type material to an n-type material. While it is unclear if phosphorus-doped $\mathrm{B}_{5} \mathrm{C}$ remains p-type, the band gap does increase by $1.6 \mathrm{eV}$ to $2.6 \mathrm{eV}$, relative to undoped $\mathrm{B}_{5} \mathrm{C}$. The n-type property of $\mathrm{Ni}-\mathrm{B}_{5} \mathrm{C}_{1+\delta}$ is consistent with $\mathrm{Fe}$ doping of $\beta$-rhombohedral boron. These results, combined with the conductivity measurements, further support the conclusions that $\mathrm{Ni}$ is incorporated into voids in the icosahedral network and that phosphorus substitutes for $\mathrm{B}$ and $\mathrm{C}$ in the chains connecting the icosahedral network.

Acknowledgements. This work was supported by AFOSR (grant number F49620-94-1-0433), the Center for Materials Research and Analysis and the W.M. Keck Center for Molecular Electronics. The work at KSU was supported by DOE. The work at the University of Idaho was supported by the University of Idaho Research Council and the Petroleum Research Foundation (PRF \# 32584-G5).

\section{References}

1. S. Lee, J. Mazurowski, G. Ramseyer, P.A. Dowben: J. Appl. Phys. 72, 4925 (1992)

2. A.A. Ahmad, N.J. Ianno, P.G. Snyder, D. Welipitiya, D. Dyun, P.A. Dowben: J. Appl. Phys. 79, 1 (1996)

3. S.-D. Hwang, D. Byun, N.J. Ianno, P.A. Dowben, H.R. Kim: Appl. Phys. Lett. 68, 1495 (1996)

4. S. Lee, P.A. Dowben: Appl. Phys. A 58, 223 (1994)

5. J. Mazurouski, S. Baral-Tosh, G. Ramseyer, J.T. Spencer, Y.-G. Kim, P.A. Dowben: In Plasma Processing and Svothesis of Materials, MRS Symposium Proceedings, ed. by D. Apelian, J. Szekely (MRS, Pittsburgh, PA 1991) Vol. 190, p. 101

6. Charles Wood: AIP Conference Proceedings 140, ed. by D. Emin, T. Aselage, C.L. Beckel, I.A. Howard, C. Wood (Albuquerque 1985) p. 206

7. A.A. Ahmad, N.J. Ianno, S.-D. Hwang, P.A. Dowben: submitted

8. D.J. Byun, B.R. Spady, N.J. Ianno, P.A. Dowben: Nanostruct. Mater. 5, $465(1995)$

9. C. Wood, D. Emin: Phys. Rev. B 29, 4582 (1984)
10. I.A. Howard, C.L. Beckel: Phys. Rev. B 35, 2929 (1987)

11. D.R. Tallant, T.L. Aselage, A.N. Campbell, D. Emin: Phys. Rev. B 40, 5649 (1989)

12. U. Kuhlmann, H. Werheit: Solid State Commun. 83, 849 (1992)

13. U. Kuhlmann, H. Werheit, K.A. Schwetz, J. Alloys Compd. 189, 249 (1992)

14. U. Kuhlmann, H. Weheit: J. Alloys Compd. 205, 87 (1994)

15. M. Carrad, D. Emin: Phys. Rev. B 51, 11270 (1995)

16. B. Morosin, G.H. Kwei, A.C. Lawson, T.L. Aselage, D. Emin: J. Alloys Comp. 226, 121 (1995)

17. S.-D. Hwang, K. Yang, P.A. Dowben, A.A. Ahmad, N.J. Ianno, J.Z. Li, J.Y. Lin, H.X. Jiang, D.N. Mcllroy: Appl. Phys. Lett. 70, 1028 (1997)

18. U. Kuhlmann, H. Werheit, T. Dose, L. Lundström: J. Alloys Compd. 186, 187 (1992)

19. H. Werheit, K. de Groot, W. Malkemper, T. Lundström: J. Less-Common Met. 82, 163 (1981)

20. H. Werheit, U. Kuhlmann, K. Shirai, Y. Kumashiro: J. Alloys Compd. 233, 121 (1996)

21. H. Werheit, U. Kuhlmann, M. Laux, R. Telle: J. Alloys Compd. 209, 181 (1994)

22. T.L. Aselage, D. Emin, G.A. Samara, D.R. Tallant, S.B. Van Deusen, M.O. Eatough, H.L. Tardy, E.L. Venturini: Phys. Rev. B 48, 11759 (1993)

23. S. Lee, T. Ton, D. Zych, P.A. Dowben: Mater. Res. Soc. Symp. Proc. 283, 483 (1993)

24. S.-D. Hwang, K. Yang, P.A. Dowben, A.A. Ahmad, N.J. Ianno, J.Z. Li, J.Y. Lin, H.X. Jiang, D.N. McIlroy: Appl. Phys. Lett. 70, 1028 (1997); S.-D. Hwang, N.B. Remmes, P.A. Dowben, D.N. McIlroy: J. Vac. Sci. Technol. B 14, 2957 (1996)

25. K. Shirai, S. Emura, S. Gonda, Y. Kumashiro: J. Appl. Phys. 78, 3392 (1995)

26. R.N. Grimes: Carboranes (Academic Press, New York 1970)

27. D.J. Byun, S.-D. Hwang, P.A. Dowben, F.K. Perkins, F. Filips, N.J. Ianno: Appl. Phys. Lett. 64, 1968 (1994)

28. K. Shirai, S. Ae, S. Gondo: In Boron Rich Solids, AIP Conference Proceedings No. 231, ed. by D. Emin, T.L. Aselage, A.C. Switendick, B. Morosin, C.L. Beckel (AIP, New York 1991) p. 336

29. H.H. Madden, G.C. Nelson, W.O. Wallace: In Boron Rich Solids, AIP Conference Proceedings No. 140, ed. by D. Emin, T.L. Aselage, C.L. Beckel, I.A. Howard, C. Wood (AIP, New York, 1986), p. 121

30. S.-D. Hwang, P.A. Dowben, A. Cheeseman, J.T. Spencer, D.N. Mcllroy: Mater. Res. Symp. Proc. 452, 1031 (1997)

31. H. Werheit, U. Kuhlmann, M. Laux, T. Lundström: Phys. Status Solidi $\mathbf{1 7 9}, 489$ (1993)

32. H. Werheit, U. Kuhlmann, G. Krach, I. Higashi, T. Lundström, Y. Yu: J. Alloys Compd. 202, 269 (1993); H. Werheit, U. Kuhlmann, T. Lundström, J. Alloys Compd. 204, 197 (1994)

33. A.G. Chynoweth, W.L. Feldmann, R.A. Logan: Phys. Rev. 121, 684 (1961)

34. R.S. Claassen: J. Appl. Phys. 32, 2372 (1961)

35. A.S. Epstein, J.F. Caldwell: J. Appl. Phys. 35, 3050 (1964)

36. E.O. Kane: Phys. Chem. Solids 2, 181 (1960)

37. E.O. Kane: J. Appl. Phys. 32, 83 (1961)

38. J. Karlovsky: Solid State Electron. 10, 1109 (1967)

39. R.A. Logan, A.G. Chynoweth: Phys. Rev. 131, 89 (1963)

40. D. Meyerhofer, G.A. Brown, H.S. Sommers Jr.: Phys. Rev. 126, 1329 (1962)

41. R.M. Minton, R. Glicksman: Solid State Electron. 7, 491 (1964)

42. J. Tauc: In Optical Properties of Solids, ed. by F. Abels (American Elsevier Publishing Co., New York 1972) p. 277

43. D. Li, W.Y. Ching: Phys. Rev. B 52, 17073 (1995)

44. U. Kuhlmann, H. Werheit, J. Pelloth, W. Keune, L. Lundström: Phys. Status Solidi B 187, 43 (1995)

45. W.K. Choi, L.J. Han, F.L. Loo: J. Appl. Phys. 81, 276 (1997)

46. H. Werheit, K. de Groot: Phys, Status Solidi B 97, 229 (1980) 